\title{
PIBID INTERDISCIPLINAR: UM OLHAR SOBRE AS CONTRIBUIÇÕES DA ARTE PARA A CONSTRUÇÃO DE OBJETOS PEDAGÓGICOS PARA PESSOAS COM DEFICIÊNCIAS
}

DOI: http://dx.doi.org/10.5965/198431781112015127

Stéfani Rafaela Pintos da Rocha ${ }^{1}$ Maria Cristina da Rosa Fonseca da Silva ${ }^{2}$

\begin{abstract}
RESUMO
O presente artigo tem como objetivo sistematizar as contribuições da arte para a construção de materiais didáticos que possibilitem, sob um viés interdisciplinar, o desenvolvimento de uma cultura inclusiva nos estudantes participantes do subprojeto PIBID - Educação Inclusiva na Escola: uma ação interdisciplinar da Universidade do Estado de Santa Catarina - UDESC. A experiência, que se iniciou em 2014, envolve três escolas de Florianópolis sendo duas delas municipais e uma estadual.

Participam do subprojeto três professoras da educação básica, uma de Língua Portuguesa, uma de Artes Visuais e uma de Música. Da universidade, participam duas professoras, sendo uma de Artes Visuais e uma de Música. Participam, igualmente, 21 estudantes das licenciaturas de Música, Artes Visuais, Pedagogia, História e Geografia e uma mestranda do programa de Pós-Graduação em Artes Visuais (PPGAV). Neste artigo, foi traçado um recorte voltado às contribuições das Artes Visuais em relação à interdisciplinaridade em uma perspectiva inclusiva. Para construir esse recorte, abordam-se, inicialmente, os fundamentos da interdisciplinaridade, os processos de artistas que desenvolvem, em sua prática, ações interdisciplinares, bem como propostas inclusivas para a construção de objetos pedagógicos a partir do PIBID Interdisciplinar UDESC. Como resultados, destaca-se a experiência de desenvolvimento de três jogos e a familiarização dos alunos com o cenário escolar.
\end{abstract}

Palavras-chave: PIBID Interdisciplinar. Inclusão. Artes. Escola. AEE.

\begin{abstract}
This article aims to systematize the art contributions to the construction of teaching materials that allow, under an interdisciplinary bias, the development of an inclusive culture in the participating students subproject PIBID - Educação Inclusiva na Escola: uma ação interdisciplinar of Universidade do Estado de Santa Catarina - UDESC. The experiment, which began in 2014, involves three schools in Florianópolis two of them municipal and state. Participate in the subproject three teachers of basic education, a Portuguese, a Visual Arts and Music. University, part two teachers, one of Visual Arts and Music. Also participated 21 students of the Bachelor of Music, Visual Arts, Education, History

\footnotetext{
${ }^{1}$ Mestranda do Programa de Pós-Graduação em Artes Visuais da Universidade do Estado de Santa Catarina UDESC.

2 É professora titular do Centro de Artes da Universidade do Estado de Santa Catarina. Atua como professora do Mestrado e doutorado em Artes Visuais da UDESC.
} 
and Geography and a master's student in the Graduate Program in Visual Arts (PPGAV). In this article, I was drawn one facing cut contributions to the visual arts in relation to interdisciplinarity in an inclusive perspective. To build this clipping, deal, initially, the fundamentals of interdisciplinarity, the processes of artists who develop in their practice, interdisciplinary actions and inclusive approach to the construction of pedagogical objects from PIBID Interdisciplinar UDESC. As a result, there is the three game development experience and familiarizing students with the school setting.

Key Words: Interdisciplinary PIBID. Inclusion. Art. School. AEE.

\section{Introdução}

O subprojeto PIBID Interdisciplinar "Educação Inclusiva na Escola: uma ação interdisciplinar" é um dos subprojetos da proposta global da UDESC, aprovado no ano de 2013 no contexto do Programa Institucional de Bolsa de Iniciação à Docência e vinculado a CAPES $^{3}$, Educação Básica. O referido subprojeto apresenta como objetivo preparar os estudantes de licenciatura para atuar em uma perspectiva inclusiva interdisciplinar em sala de aula em parceria com o Atendimento Educacional Especializado (AEE) 4 .

$\mathrm{O}$ setor de Atendimento Educacional Especializado "é um serviço da educação especial que identifica, elabora, e organiza recursos pedagógicos e de acessibilidade, que eliminem as barreiras para a plena participação dos alunos, considerando suas necessidades específicas" (SEESP/MEC, 2007). Para seu êxito, conta com a articulação entre professores, equipe pedagógica e famílias na proposição de ações conjuntas. Essa aproximação com o AEE precisa ser construída na formação inicial a fim de criar uma cultura inclusiva e estimular a criação de materiais pedagógicos gerando situações de aprendizagem para estudantes com deficiência e demais estudantes. Ocorre que, na maioria dos casos, o tema da inclusão é introduzido nas matrizes

\footnotetext{
${ }^{3}$ Coordenação de Aperfeiçoamento do Pessoal de Ensino Superior (CAPES) que, a partir do governo Lula, pelo sucesso das propostas de formação para o Ensino Superior, conquistou, por meio de um desdobramento - Capes Educação Básica -, o papel de propositor de políticas de ação para a formação docente.

${ }^{4}$ As atividades, pela sua dimensão articulada de ensino, pesquisa e extensão, recebem recursos da CAPES, CNPq, UDESC e Fapesc.
} 


\section{EDUCAÇÃO, ARTES}

VOLUME 11, NÚMERO 1, Ano 2015

E INCLUSÃO

ISSN 1984-3178

curriculares com a criação de uma ou duas disciplinas para atender à legislação e poucas ações conjuntas atravessam interdisciplinarmente os currículos propiciando uma formação para isso. Com a intenção de enfrentar essa problemática neste projeto, cada equipe escolar foi formada por estudantes de licenciatura nas áreas de Música, Pedagogia, Geografia, História e Artes Visuais, que contemplam a maioria das licenciaturas do Campus I da instituição, ampliando, assim, as relações entre a sala de aula, o professor e a sala de AEE, totalizando 21 participantes e envolvendo três escolas.

O Grupo de Pesquisa Educação, Artes e Inclusão ao qual o projeto está vinculado já possui trabalhos na área de pedagogia, música e artes visuais a partir das necessidades levantadas nas escolas, como as áreas de geografia e história, que apresentam necessidades de adaptação de materiais educativos tanto nas séries iniciais quanto nas finais do ensino fundamental, contando com a participação de outros professores de apoio na equipe.

O projeto desenvolveu, em seu primeiro ano, um conjunto de atividades dentre as quais se destaca a realização de um diagnóstico das ações de inclusão na escola, buscando identificar e problematizar as necessidades da prática inclusiva interdisciplinar na sala de aula. Para desenvolver tal tarefa, os bolsistas utilizaram a observação e o registro e buscaram compreender os modos de fazer e refletir dos professores, bem como sua experiência na condução das propostas de trabalho.

Outro aspecto abordado analisou as proposições da legislação, o contexto no qual as unidades educacionais estão inseridas e suas condições de estrutura física, os interesses das famílias e as propostas do setor de AEE e como são desenvolvidas suas ações na escola com os alunos que apresentam deficiência. Esse diagnóstico foi utilizado como fio condutor para o desenvolvimento das atividades e construção do jogo $I^{5}$ ao longo do primeiro ano do projeto.

\section{Fundamentos interdisciplinares: principais conceitos}

\footnotetext{
${ }^{5}$ Jogo I foi o nome dado a primeira atividade de criação de jogos no PIBID Interdisciplinar. Trata-se deste modo do conjunto formado pelo primeiro jogo de cada bolsista participante.
} 
Conforme Barbosa (2008), atualmente se vive na era "inter", visto que todos estão rodeados pela internet, interação e interculturalidade, chegando-se ao conceito da interdisciplinaridade. Porém, este último termo tem sido recorrente para a área de artes visuais quando, por exemplo, depara-se com as obras de arte contemporânea que, por sua vez, necessitam do conhecimento de profissionais de outras áreas para que se concretizem. De fato, a interdisciplinaridade revela o quão importante é o saber específico. Nos anos 70, o professor de artes atuava de forma polivalente ao ministrar aulas de artes visuais, música, dança e teatro, fornecendo um conhecimento superficial das quatro linguagens artísticas aos alunos, fruto da política de formação aligeirada do governo militar.

A interdisciplinaridade passou a ser alvo de discussões a partir dos anos 60, primeiramente na França e Itália, chegando ao Brasil em 1961 por meio de um projeto criado pelo professor e filósofo francês Georges Gusdorf, apresentado à UNESCO em 1983 e visava estreitar os laços teóricos entre as ciências humanas. Quem deu continuidade aos estudos de Gusdorf, no Brasil, foi Hilton Japiassú (1976), seguido de Ivani Fazenda (1979). Esses três autores apresentam semelhanças em seus pontos de vista com relação ao conceito da interdisciplinaridade, já que a definem como uma fonte de troca entre diferentes especialistas em prol de um mesmo objeto de pesquisa. Consideram ainda que a interdisciplinaridade tratase de um conceito que gera diferentes interpretações.

O termo interdisciplinaridade não possui um sentido único e estável. Trata-se de um neologismo cuja significação nem sempre é a mesma e cujo papel nem sempre é compreendido da mesma forma (FAZENDA, 1979, p. 25).

Lucídio Bianchetti e Ari Jantsch (2010) assinalam que pesquisadores como Japiassú (1976), Gusdorf (1983) e Fazenda (1979) apontam uma "receita" para a solução dos problemas educacionais, como a superação da divisão curricular das disciplinas, bem como da não fragmentação do trabalho em grupo. Esses autores sugerem que, para constituir-se uma proposta interdisciplinar dentro da escola, faz-se necessária uma equipe disposta ao novo, assim como professores que apresentem um objetivo em comum, e que seja interesse de todos os envolvidos solucionar algum "problema" na escola.

Estas ideias convergem com a posição de Ana Mae Barbosa (2008, p.1) quando menciona que a "[...] interdisciplinaridade não é polivalência" por se tratar de um trabalho em 


\section{EDUCAÇÃO, ARTES}

VOLUME 11, NÚMERO 1, Ano 2015

E INCLUSÃO

ISSN 1984-3178

grupo com diferentes especialistas agindo em favor de um mesmo objetivo por meio do qual surgirão as conexões entre as diversas áreas.

Tendo em vista a visão de diferentes autores que investigam o conceito da interdisciplinaridade, este artigo compartilha dos pensamentos de Barbosa (2008), Bianchetti e Jantsch (2010), autores que, mesmo em correntes epistemológicas diferentes, apresentam pontos de convergências em especial no modo como visualizam, na prática, uma ação interdisciplinar. Eles desenvolvem suas teorias partindo de diferentes lugares: a primeira autora é da área de artes visuais e os outros dois, das ciências humanas pautados no materialismo dialético.

Concordamos quando Barbosa (2008) diz que, tratando-se da arte, esta tende a interdisciplinarizar-se por estabelecer relações com os outros campos do saber respeitando a especificidade de cada área e atuando em conjunto com outras pessoas que detêm a competência específica sobre determinado assunto. Considerando que o saber específico que cada profissional apresenta sobre determinada área do conhecimento é fundamental para que se constitua um trabalho sólido em grupo de cunho interdisciplinar, é importante valorizar também o saber disciplinar que se encontra na matriz curricular das universidades e escolas.

Sobretudo, a arte é, em suma, de natureza interdisciplinar por se efetivar na articulação de competências e habilidades nos diversos campos do saber, fornecendo dessa forma, um conhecimento mais aprofundado aos alunos.

A interdisciplinaridade pode ser vivenciada de diversas maneiras, mas, para que os alunos aprendam um determinado assunto por esse viés, é necessário que professores de diferentes áreas construam um projeto integrado a fim de que, com seus conhecimentos específicos, contribuam para o aprendizado mais globalizante sobre um determinado assunto, bem como possam enriquecer as produções dos alunos em vista das relações quando conseguem perceber que o saber sobre um objeto de estudo ultrapassa a especificidade da disciplina.

Entre as considerações não epistemológicas, inclui a necessidade de identificação da ideia dominante, isto é, deve haver reconhecimento claro da ideia ou problema que servirá do foco central para o trabalho. Não só a ideia deve ser percebida por todos os participantes, mas também considerada de interesse por todos os participantes. 
Também é crucial a necessidade de alcançar um resultado, chegar ao fim do projeto ou pesquisas ou, ainda de chegar a formular respostas para o problema escolhido. Sem isso, não chegamos a uma síntese transformadora (BARBOSA, 2008, p. 06).

Para tanto, quando se idealiza um projeto envolvendo várias áreas, é necessário que ocorra o esclarecimento do que será investigado e solucionado dentro da proposta de trabalho. É preciso que fique claro qual o problema de pesquisa e de intervenção no local em que se propõe a pesquisa, visto que não basta apenas criar um grupo com pesquisadores que investiguem diversos assuntos, mas sim que tenham um interesse em comum, ou seja, que se disponham a fornecer o que sabem sobre assunto em prol de um ambiente de interlocução que visa a melhoria e transformação dos processos de aprendizagem.

Os estudantes, após observarem algumas turmas com alunos que apresentam deficiência incluídos na sala de aula regular, puderam ver a interação entre os alunos, a atitude do professor da sala, bem como os recursos utilizados, dentre eles, podemos destacar os jogos disponibilizados pela prefeitura de Florianópolis-SC que visam desenvolver o raciocínio lógico, concentração e estreitar as relações interpessoais. Entretanto, a partir das visitas realizadas nas escolas alguns acadêmicos identificaram que os professores na medida do possível tentam incluir os alunos com deficiência em todas as atividades e que alguns adaptam os materiais fornecidos nas escolas, para que mais estudantes possam participar. Esses diferentes olhares sobre um determinado objeto de pesquisa servem como foco de intervenção e realização de propostas interdisciplinares a partir do ponto de vista de cada acadêmico e sua área de conhecimento.

Nesse sentido, após as primeiras observações no espaço escolar com foco na inclusão tratando-se de efetivar a proposta do PIBID interdisciplinar, os licenciandos desenvolveram algumas oficinas, como a de fotografia seguida de uma exposição na escola das fotos realizadas com os alunos, a construção de uma árvore não convencional com alunos da educação infantil e aulas de violão buscando atender, de alguma forma, às demandas da escola por atividades extracurriculares.

A interdisciplinaridade caracteriza-se pela rede de interação entre os diferentes especialistas, pelas relações estabelecidas e pela gama diversa de saberes creditados em um 


\section{EDUCAÇÃO, ARTES}

VOLUME 11, NÚMERO 1, Ano 2015

E INCLUSÃO

ISSN 1984-3178

problema comum de investigação. No entanto, é preciso conhecer as partes, o saber disciplinar para se alcançar o todo, ou seja, realizar um trabalho interdisciplinar em equipe.

\section{As contribuições da arte numa perspectiva inclusiva}

Para refletir acerca da contribuição da arte em uma perspectiva inclusiva é necessário analisar como um produto social situado historicamente, transformando-se ao longo da história e ocupando diferentes papéis sociais é reconstruído em cada contexto. É certo que nenhuma cultura prescindiu do processo criador e a imagem acompanha a humanidade desde os primórdios, muito antes da fala e da escrita, atingindo seu ponto máximo na contemporaneidade em que a maior parte dos processos comunicacionais são mediados pela imagem. Por outro lado a imagem atualmente é tão popular que na maioria das vezes não nos damos conta de seu conteúdo, é como se a visualização de imagens tornou-se automatizada.

O artista, por sua vez, aborda uma diversidade de temas, os quais ora focam-se no mundo, ora na religiosidade, ora na representação do próprio homem. Ernest Fischer (1981, p. 17) defende a arte, identificando-a como um processo de necessidade humana. Para o autor "[...] toda arte é condicionada pelo seu tempo e representa a humanidade em consonância com as ideias e aspirações, as necessidades e as esperanças de uma situação histórica particular". De fato, o autor resgata o aspecto mágico da arte característico dos primórdios da humanidade e suas transformações ao longo da história. Ele ressalta o papel da arte na atualidade como possibilidade de conhecer e mudar o mundo, no entanto, destaca as características subjetivas da arte. Ainda, nas palavras do autor, "[...] a arte também é necessária em virtude da magia que lhe é inerente" (FISCHER, 1981, p. 20).

Esse caráter mágico confere a imprevisibilidade do objeto artístico possibilitando seu trânsito em diferentes contextos e, ao mesmo tempo, possibilitando um registro histórico aos objetos que atravessam o tempo e inquietam até os dias atuais.

A experiência estética é caracterizada por uma certa qualidade da sensação e está mais próxima do estranhamento e da problematização do que da mera experiência de reconhecimento. Ela afeta, surpreende, mobiliza, espanta, faz pensar e provoca uma suspensão na nossa maneira habitual de perceber e viver (KASTRUP, 2010, p. 53). 


\section{EDUCAÇÃO, ARTES}

Considerando que a escola é o espaço privilegiado onde as camadas populares têm acesso aos conhecimentos artísticos e que a aula de artes reúne as melhores condições para esse exercício, a experiência estética precisa ser estimulada, desenvolvida e ampliada no espaço educativo a fim de que as imagens possam ser lidas criticamente. As crianças com deficiência necessitam de atenção especial nesse quesito, tanto para a adaptação de materiais, quanto para a ampliação do repertório. Pela dificuldade de acessibilidade, mesmo em cidades com farto aparelho cultural, as famílias enfrentam barreiras para usufruírem das atividades culturais da cidade, mesmo quando os custos dessa participação são isentos. Mais uma vez, é a escola que consegue romper algumas dessas barreiras e possibilita um acesso físico mais imediato por meio de visitas agendadas junto aos setores educativos dos museus.

Nieves (2010) apresenta a experiência de trabalho com pessoas com deficiência e demais públicos a partir da arte ${ }^{6}$ em um espaço expositivo em Madri, Espanha, intitulado "La Casa Encendida". A proposta segue tendências contemporâneas de desenvolvimento de espaços expositivos e distancia-se da ideia de cubo branco, ao mesmo tempo em que apresenta uma diversificada programação social para diferentes públicos. Segundo a autora, "La Casa Encendida" é um edifício destinado à difusão e criação contemporânea, assim como um lugar produtor de processos de reflexão e debate em torno de valores não só artísticos, mas também éticos.

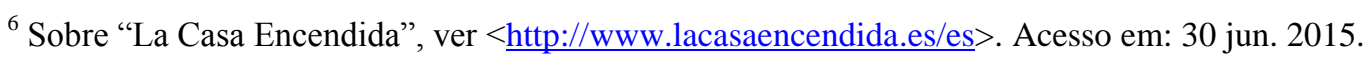




\section{EDUCAÇÃO, ARTES VOLUME 11, NÚMERO 1, Ano 2015 E INCLUSÃO

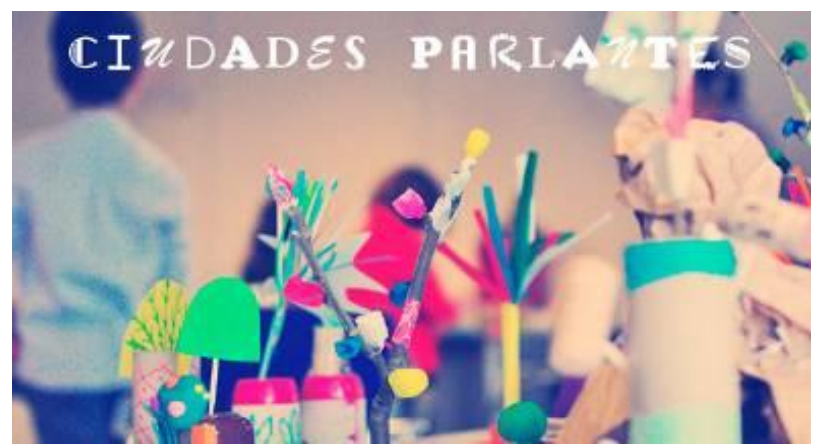

Figura 1: Cidades Falantes

Fonte: Disponível em: <http://www.lacasaencendida.es/es/cursos/ciudades-parlantes-4422〉. Acesso em: 30 jun 2015.

Igualmente, o espaço deseja difundir valores de solidariedade e respeito ao meio ambiente, assim como oferecer formação, propondo debates sobre temas diferentes como globalização, mudanças climáticas ou mesmo as últimas novidades em matéria de cine, teatro e dança.

Dentre os princípios de "La Casa Encendida" está a proposta de atender, de forma integral e em igualdade de condições, às pessoas com deficiência. Para atingir essa meta, a instituição apresenta um espaço acessível, uma equipe multidisciplinar e um plano de trabalho que considera processos de participação plena.

No Brasil, diferentes instituições buscam ampliar suas ações para atender ao público com deficiência, mas ainda o quantitativo de ações é pequeno. A UDESC vem, desde 2013, desenvolvendo o projeto de extensão "Família no Museu"7 que proporciona a ampliação das experiências estéticas das famílias com filhos com deficiência. Para tanto, convida mensalmente famílias para participar no final de semana de uma atividade em um dos museus da cidade. As famílias, no entanto, apresentam dificuldades de deslocamento em relação à falta de adaptação e poucos horários dos transportes públicos, bem como dificuldades de acesso por necessidade de maior acessibilidade nos prédios históricos que alojam alguns dos museus da cidade. O projeto vem, aos poucos, ampliando seu potencial, conquistando novos espaços de divulgação e despertando a necessidade de uma cultura inclusiva nos espaços culturais. Nas atividades do projeto Família no Museu, além de acesso a uma mediação

\footnotetext{
${ }^{7}$ O projeto é coordenado pela professora Maria Cristina da Rosa Fonseca da Silva, do PPGAV - UDESC. Sobre o projeto, ver Farias (2014).
} 


\section{EDUCAÇÃO, ARTES}

VOLUME 11, NÚMERO 1, Ano 2015

E INCLUSÃO

ISSN 1984-3178

especializada os participantes também participam com suas famílias de uma oficinas articulada com o tema da exposição.

Ao longo dos anos, o Grupo de Pesquisa Educação, Artes e Inclusão vem desenvolvendo ações que problematizam experiências de arte e inclusão tanto nos aspectos da produção de objetos artísticos acessíveis como no da aproximação dos públicos com deficiência da arte. A adaptação de materiais e objetos inclusivos é uma das possibilidades de qualificação da experiência estética de públicos com deficiência.

\section{A produção de objetos pedagógicos: desenvolvimento dos jogos}

Conforme Fonseca da Silva, Mendes e Schambeck (2012), os objetos pedagógicos consistem em um material criado pelos professores, que podem ser objetos prontos ou adaptados com a finalidade de suprir uma necessidade e garantir o desenvolvimento de uma atividade de maneira autônoma por parte do aluno. Além disso, a acessibilidade que esses materiais fornecem ao educando com deficiência também garante que esse sujeito amplie suas habilidades e potencialize sua aprendizagem.

No subprojeto PIBID "Educação Inclusiva na Escola: uma ação interdisciplinar” os estudantes de artes visuais, música, pedagogia, história e geografia desenvolveram os primeiros jogos pedagógicos, interdisciplinares e inclusivos, tendo como referência, para a construção desses materiais, as observações realizadas por eles próprios nas escolas do PIBID. Nessa ação, os pibidianos observaram os alunos que apresentavam diagnóstico de alguma deficiência, bem como fizeram leituras sobre o assunto e conversaram com os professores supervisores envolvidos na pesquisa e coordenadores de área da UDESC.

Para a criação dos jogos, os bolsistas consideraram as etapas propostas por Fonseca da Silva (2010) bem como as atividades planejadas pelo projeto PIBID Interdisciplinar, iniciando pela: 1- coleta das necessidades, de materiais disponíveis na escola e dos projetos; 2- início da produção e estudo do uso dos materiais, bem como o processo de construção das propostas, considerando a análise de professores especialistas (AEE) para a realização dos materiais pedagógicos e 3 - esta etapa consiste na experimentação dos projetos e criação final dos 


\section{EDUCAÇÃO, ARTES}

VOLUME 11, NÚMERO 1, Ano 2015

jogos, tendo por objetivo aplicar com os estudantes para viabilizar a proposta e perceber a interação que promove.

Após um ano de participação no PIBID, os acadêmicos criaram os jogos articulando sua área de formação com duas outras áreas envolvidas no projeto, assim como revelaram o envolvimento e criatividade em seus primeiros materiais pedagógicos. No total, foram elaborados doze jogos (três envolvendo a área artes visuais) com a proposta de auxiliar os processos de aprendizagem dos alunos da sala de aula regular, principalmente daqueles que apresentam deficiência.

Os licenciandos de Artes Visuais que atuam no projeto desenvolveram materiais que envolvem a história da arte e os fundamentos da linguagem visual. Para isso, alguns deles se serviram de materiais simples, como imagens de obras de artes coletadas na internet, e outros adaptaram jogos já existentes e modificaram as imagens e regras, como, por exemplo, o jogo Dominando (Figura 2), e o jogo de Memória, Texto e Imagem (Figura 3).

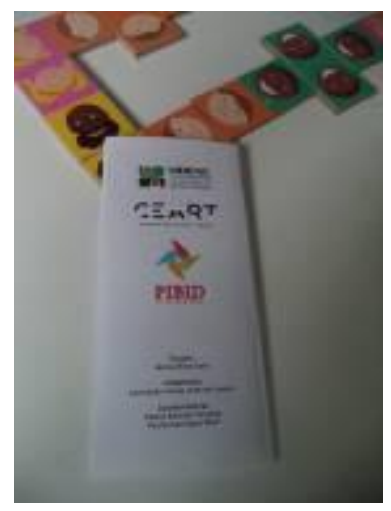

Figura 2: Jogo Dominando Expressões Faciais.

Fonte: Arquivo da coordenadora de Artes Visuais do PIBID (2014).

O jogo "Dominando Expressões Faciais" foi inicialmente criado para um aluno com autismo da turma G6C da Escola Básica Municipal Virgílio dos Reis Várzea. O bolsista de Artes Visuais, elaborou o jogo individualmente e, depois, recebeu auxílio de outra licencianda do mesmo curso. Seu material foi confeccionado a partir de um jogo existente, intitulado "Dominando", que apresenta expressões faciais com seis rostos diferentes de crianças. O material é feito em MDF e as imagens foram fixadas e protegidas com papel contact para 


\section{EDUCAÇÃO, ARTES}

VOLUME 11, NÚMERO 1, Ano 2015

preservar o jogo e garantir maior durabilidade. Suas dimensões são $5 \mathrm{~cm}$ x $10 \mathrm{~cm}$ de cada peça, sendo mais de 20 peças ao todo.

O material pode ser utilizado por quatro crianças, seguindo as orientações do encarte criado pelo bolsista, que contém seis possibilidades de realizar o jogo.

Nesse material, percebe-se que o conteúdo de Artes Visuais foi abordado evidenciando características de socialização e de expressividade. Com exceção das cores, nenhum conteúdo de Artes Visuais foi abordado. Também os alunos não realizaram encontros com as professoras do AEE da escola 3 para mostrar o material criado a fim de que pudessem realizar outras modificações no material, mas realizaram visitas na sala de recursos para conhecer os materiais elaborados pelas educadoras especiais. No entanto, após confeccionado o material pedagógico, os licenciandos que realizaram essa proposta de jogo visitaram a sala do AEE da escola novamente este ano e conheceram as adaptações feitas pelas educadoras especiais, como jogos de encaixe, de raciocínio lógico, memória, entre outros. Em suas falas, após a visita e visualização dos materiais criados pelas professoras da sala de recursos, eles manifestaram que foi um encontro produtivo que forneceu ideias para os próximos materiais pedagógicos, tais como: a quantidade de peças para ser utilizada com todos os alunos ao mesmo tempo, regras e tamanho do material.

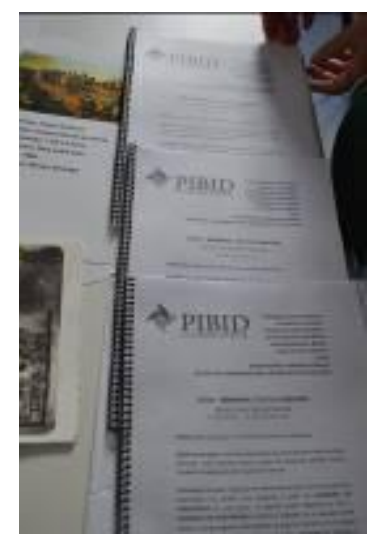

Figura 3: Memória, Texto e Imagem (Revoltas e Resistências).

Fonte: Caderno de questões elaborado pelos bolsistas PIBID de Artes Visuais e História (2014).

O jogo "Memória, Texto e Imagem (Revoltas e Resistências)" apresenta quatro cadernos contendo regras, imagens, questões e respostas, envolvendo a área de Artes Visuais 


\section{EDUCAÇÃO, ARTES}

VOLUME 11, NÚMERO 1, Ano 2015

E INCLUSÃO

ISSN 1984-3178

e História, pois foi construído em parceria com um licenciando da História. A questão central do jogo é "Qual imagem corresponde a esta pergunta?".

A proposta do material apresenta algumas orientações, como poder ser aplicada com alunos dos sétimos, oitavos e nonos anos do Ensino Fundamental na Escola Básica Estadual Hilda Teodoro Vieira. Para tanto, devem-se organizar dois grupos: um com a responsabilidade de realizar uma pergunta a partir do caderno de perguntas ao outro grupo. Além disso, o segundo grupo responde com o auxílio do caderno de respostas, apresentando uma justificativa da resposta. De acordo com o guia do jogo, elaborado pelos licenciandos, os participantes que acertarem a resposta continuavam a jogar e, para isso, iniciavam o jogo da memória e, se a resposta estiver correta, permaneceria jogando até errar ou finalizar o jogo. No entanto, se a resposta for incorreta, o outro grupo começaria o jogo da memória seguindo as mesmas orientações. Também participaria um professor/mediador utilizando o caderno mediador que contém as perguntas com as imagens de resposta. Por último, o encerramento do jogo da memória aconteceria quando todas as imagens forem encontradas e ganharia quem obtiver maior pontuação, ou seja, quem descobrir o maior número de imagens.

Para iniciar o jogo e pensar sobre seu direcionamento foi desenvolvido um período de convivência com os estudantes com deficiência por vários meses. Observaram-se as dificuldades que os alunos enfrentavam na sala de aula, pois alguns não sabem ler e escrever, e, então, levantou-se a possibilidade de trabalho com o material. Essa pesquisa prévia foi essencial para o projeto e, ao mesmo tempo, estimulou um compromisso com o jogo que trouxe alguns elementos de complexidade. Os licenciandos buscavam, de fato, interferir na aprendizagem e não somente desenvolver uma experiência de jogo. Por vários meses, eles ficaram desenvolvendo seus projetos, as ideias surgiam, mas nem sempre elas se traduziam em projetos prontos. 


\section{EDUCAÇÃO, ARTES}

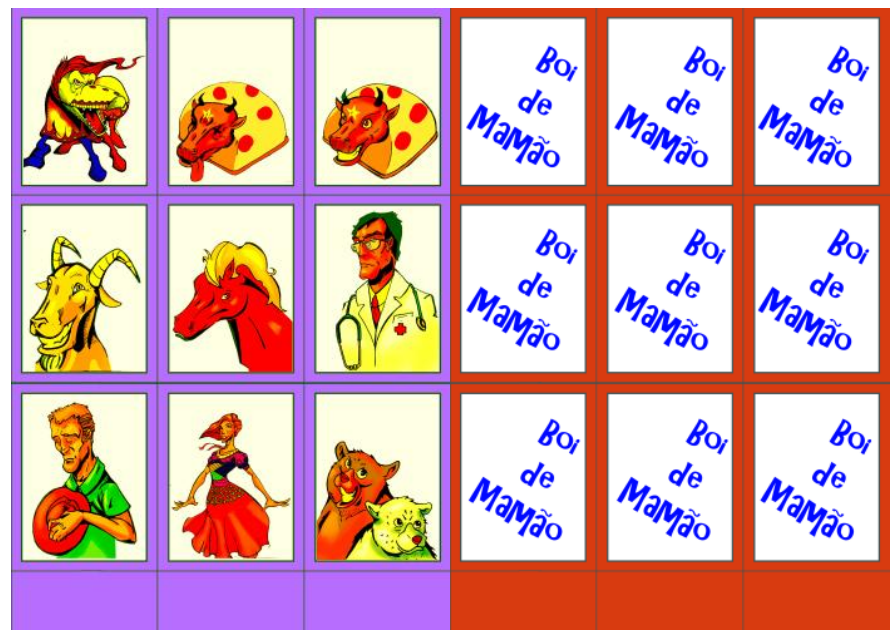

Figura 4: Jogo de Memória Boi de Mamão.

Fonte: Arquivo do bolsista Gustavo (2014).

A Escola Luiz Cândido da Luz desenvolveu um projeto de Boi de Mamão na escola. O boi é um folguedo popular ${ }^{8}$ que consiste em uma dança realizada por diferentes personagens em torno de um boi que morreu e que precisa ser ressuscitado. Para incluir as crianças com deficiência, a professora de música, em conjunto com os alunos, desenvolveu, em 2014, personagens adaptados para que as crianças com deficiência pudessem participar da brincadeira do boi. Um dos alunos também desenvolveu um jogo de memória com os personagens do Boi de Mamão, destacando a linguagem dos desenhos animados, já que em suas intervenções realizadas em sala de aula, propôs uma oficina de desenho.

A proposta surgiu a partir das observações realizadas na Escola Básica Municipal Luiz Cândido da Luz, na turma 53 do quinto ano, em que estudava um aluno com o diagnóstico de Síndrome de Willians. Além disso, o bolsista de Artes Visuais desenvolveu, nessa turma, uma oficina de desenho, bem como estabeleceu algumas aproximações com o aluno, apresentando histórias em quadrinhos. O material foi impresso em papel cartão de tamanho A4, e não apresenta adaptações; são cartas com imagens, sem palavras. Uma possibilidade de modificar esse jogo, segundo seu autor, é inserir o nome de cada personagem da carta para que o aluno associe a imagem com a palavra. Ao todo, são nove imagens diferentes que envolvem

\footnotetext{
${ }^{8}$ Sobre o folguedo, ver <http://www.manezinhodailha.com.br/subweb_portalboidemamao.htm $>$. Acesso em: 30 jun. 2015.
} 


\section{EDUCAÇÃO, ARTES}

personagens do folclore catarinense, que são: Boi de Mamão, vaqueiro Mateus, o médico, o cavalo, ursos, jaraguá, Bernúncia, cabra e a Maricota (Figura 4).

Esses três jogos foram os primeiros desenvolvidos totalmente durante o primeiro ano do subprojeto PIBID “Educação Inclusiva na Escola: uma ação interdisciplinar" pelos licenciandos em Artes Visuais, juntamente com outras áreas que participam do projeto, como a História. Inicialmente, percebeu-se, por meio das reuniões realizadas com todos os bolsistas, a dificuldade em iniciar a realização do jogo, bem como de adaptá-lo. Notou-se, também, que a maior dificuldade em inserir o conteúdo específico da área foi dos bolsistas de Artes Visuais, com exceção de um deles, que conseguiu inserir imagens de obras de arte relacionadas com história brasileira. Os demais jogos de Artes não apresentaram nitidamente o conteúdo da área, pois partiram de jogos já existentes e não desenvolveram outra proposta associada à sua área do conhecimento articulada com outro campo do saber. A música, por exemplo, mesmo compartilhando o tema com outra área, teve enfatizada a sua área de conhecimento.

\section{Considerações finais}

Como resultado do desenvolvimento em um ano e meio do projeto, houve a valorização das atividades conjuntas desenvolvidas entre professores, estudantes PIBID, famílias e AEE, por meio de relato de publicações conjuntas, estimulando uma produção bibliográfica por escola.

Entende-se que os jogos poderão auxiliar na aprendizagem, constituindo-se em uma ferramenta para o domínio de conteúdos disciplinares e interdisciplinares, para o desenvolvimento de práticas inclusivas e aprimoramento de abordagens metodológicas de trabalho em grupo pelos participantes. Para isso, estimula-se, ao longo do subprojeto, o registro de relatórios a serem disponibilizados para as escolas, bem como a realização de oficinas para os bolsistas e para a comunidade escolar. 


\section{EDUCAÇÃO, ARTES}

VOLUME 11, NÚMERO 1, Ano 2015

E INCLUSÃO

ISSN 1984-3178

Como estímulo para uma docência mais qualificada, buscou-se incrementar os processos de escrita reflexiva por parte dos professores e estudantes PIBID, desenvolvendo formas de participação nas oficinas de escrita e de escrita acadêmica, buscando a divulgação da produção.

Já o desenvolvimento de materiais didáticos para serem utilizados pelos estudantes com deficiência na escola, bem como pelos demais estudantes é a tarefa principal do projeto. Contudo, mesmo que exista uma parceria com o setor de AEE, o tipo de material construído apresenta forma e função diferenciadas dos materiais adaptados pelos setores de AEE, pois, enquanto o material proposto pelo AEE tem como objetivo servir de ferramenta para auxiliar uma necessidade sensorial, o objeto pedagógico tem como objetivo auxiliar o desenvolvimento cognitivo.

Cada escola desenvolveu um conjunto de, no mínimo, cinco jogos disponibilizados em um segundo momento para experimentação junto à escola, abordando diferentes conteúdos de artes, geografia, história e pedagogia. Porém, dos três jogos relatados, apenas um deles contemplou a proposta do subprojeto PIBID, enfatizando a interdisciplinaridade para a construção do jogo. Esse aspecto vem sendo trabalhado no projeto para a preparação do segundo jogo.

Percebe-se, que para atingir todos os alunos da turma usufruindo do mesmo recurso, dependendo da deficiência isso é possível, com exceção de alguns alunos com autismo que exigem o desenvolvimento de abordagens mais específicas para obter o sucesso da participação.

Tais observações revelam que para a elaboração de novos jogos, os bolsistas necessitam dialogar e envolver também os professores da sala de aula regular, já que estes atuam diariamente com os alunos e sabem de suas habilidades e dificuldades. As observações realizadas foram valiosas para que estes acadêmicos conhecessem o contexto escolar, bem como a rotina dos alunos. Porém, muitas vezes essa inserção na sala de aula inicia com uma observação, limitando o observador de intervir e conhecer melhor os estudantes. A docência pressupõe uma interação maior, sendo fruto do desejo do bolsista de intervir nessa realidade e não uma obrigação imediata. 


\section{EDUCAÇÃO, ARTES}

VOLUME 11, NÚMERO 1, Ano 2015

E INCLUSÃO

ISSN 1984-3178

No caso específico dos bolsistas de Artes Visuais, além das observações realizadas eles buscaram contribuir com as professoras da sala de aula regular, realizando oficinas, exposição e propondo atividades para a turma quando possível. Atuar no contexto da diversidade de uma sala de aula requer muito estudo, planejamento e recursos para este fim, bem como de um professor motivado e comprometido.

Pensar no jogo a partir do conteúdo específico que se quer ensinar aos alunos, considerando a dificuldade de todos e não somente do aluno que apresenta deficiência, permite que esse recurso possa ser inserido em qualquer contexto. Ademais, propor várias regras para um mesmo material é importante, visto que nem sempre são compreendidas de início. Somado a isso, a questão visual do jogo também é um diferencial para atingir o objetivo, já que muitos dos jogos comumente utilizados por crianças e adolescentes, são coloridos e sonoros. Por outro lado, necessita também ter o cuidado de não inserir muitas informações para não gerar confusão nos alunos, fazendo com que desistam do jogo. É importante destacar, que não basta a estética do jogo, senão considerar sua funcionalidade, sua ludicidade e sua proposta pedagógica tendo como propósito ensinar sobre arte para os alunos com ou sem deficiência.

Buscou-se, finalmente, investir na melhoria das relações interpessoais entre professores/AEE e famílias, contribuindo para o trabalho conjunto do grupo, na mediação de encontros, desenvolvimento de atividades conjuntas, cursos e oficinas, e em uma maior produção de objetos pedagógicos ao longo dos próximos anos.

\section{Referências}

BARBOSA, Ana Mae. Arte na Educação: interterritorialidade refazendo interdisciplinaridade. In: Revista Design, Arte e Tecnologia 4. São Paulo: Rosari, Universidade Anhembi Morumbi, PUC - Rio; Unesp - Bauru, 2008. 


\section{EDUCAÇÃO, ARTES \\ E INCLUSÃO}

VOLUME 11, NÚMERO 1, Ano 2015

ISSN 1984-3178

BIANCHETTI, Lucídio; JANTSCH, Ari Paulo. Interdisciplinaridade e práxis pedagógicas: tópicos para discussão sobre possibilidades, limites, tendências e alguns elementos históricos e conceituais. In: Ensino em Re-vista, 2010 (1): 7-25, jul. 01./jul. 02.

BRASIL, MEC/SEESP. Política nacional de educação especial na perspectiva da educação inclusiva. $2007 . \quad$ Disponível em: <http://portal.mec.gov.br/arquivos/pdf/politicaeducespecial.pdf $>$. Acesso em: 30 ago. 2015.

FARIAS, Raysa Serafim. Um encontro com o projeto família no museu. In: Revista Educação, Artes e Inclusão. V 10, n.02, 2014. p. 170 a 182. Disponível em: <http://www.revistas.udesc.br/index.php/arteinclusao/article/view/6026>. Acesso em: 27 de fev. 2015.

FAZENDA, Ivani Catarina Arantes. Integração e interdisciplinaridade no ensino brasileiro: efetividade ou ideologia. São Paulo: Loyola, 1979.

FISCHER, Ernest. A necessidade da arte. Rio de Janeiro: Editora Zahar, 1981.

FONSECA DA SILVA, Maria Cristina da Rosa; MENDES, Regina Finck; SCHAMBECK, Geovana M. L. Objetos pedagógicos: uma experiência inclusiva em oficinas de artes. Araraquara, SP: Junqueira\&Marin, 2012.

GUSDORF, Georges. Pasado, presente y futuro de la investigación interdisciplinaria. In: APOSTEL, G. et al. Interdisciplinariedad y Ciências Humanas. Madrid, Tecnos/Unesco, 1983.

JAPIASSU, Hilton. Interdisciplinaridade e patologia do saber. Rio de Janeiro: Imago Editora Ltda, 1976.

KASTRUP, Virgínia. Atualizando virtualidades: construindo a articulação entre arte e deficiência visual. In. MORAES, Marcia; KASTRUP, Virgínia (Org.). Exercícios de ver e não ver: arte e pesquisa com pessoas com deficiência visual. Rio de janeiro: Editora Nau, 2010 .

NIEVES, Maria Blanca Rosilio. La Casa Encendida. In: ARBONÉS, Tais Vidal (Org.). Arte Contemporáneo y educación especial. Espanha: Ajuntamiento de Lleida, 2010. 